\title{
Tumor cellular proliferation is associated with enhanced immune checkpoint expression in stage I non-small cell lung cancer
}

\author{
Kyle G. Mitchell, MD, ${ }^{a}$ Edwin R. Parra, MD, PhD, ${ }^{\mathrm{b}}$ David B. Nelson, MD, ${ }^{\mathrm{a}}$ Jiexin Zhang, MS, \\ Ignacio I. Wistuba, MD, ${ }^{\mathrm{b}}$ Junya Fujimoto, MD, PhD, ${ }^{\mathrm{b}}$ Jack A. Roth, MD, ${ }^{\mathrm{a}}$ and Mara B. Antonoff, MD, ${ }^{\mathrm{a}}$ the \\ MD Anderson Lung Cancer Immune Microenvironment Working Group
}

\section{ABSTRACT}

Objectives: Ki67 is a marker for tumor proliferative activity and is known to have prognostic significance in multiple solid malignancies. We sought to characterize the relationships among Ki67 expression, immune cell infiltration, and immune checkpoint expression in patients with resected non-small cell lung cancer.

Methods: Specimens of patients undergoing resection of stage I to III non-small cell lung cancer (1997-2012) were analyzed using tissue microarrays. Proliferative index was quantified as the percentage of malignant cells expressing Ki67. Checkpoints expressed on malignant cells (programmed death ligand 1, B7H3, B7H4, indoleamine 2,3-dioxygenase 1) and lymphocytes (T-cell immunoglobulin and mucin-domain containing 3, V-domain suppressor of T-cell activation, tumor necrosis factor receptor superfamily member 4 , lymphocyte activation gene 3 , inducible T-cell co-stimulator) were analyzed in intratumoral and stromal compartments, respectively. Immune cell densities were quantified in intratumoral and peritumoral compartments in a representative subset.

Results: A total of 190 patients met inclusion criteria. Higher Ki67 expression was noted in squamous cell carcinoma (median $31.4 \%$ positive malignant cells vs $15.2 \%$ adenocarcinoma, $P<.001)$, advanced-stage tumors $(25.7 \%$ stages II/III vs $20.8 \%$ stage I, $P=.013)$, and poorly differentiated tumors $(28.8 \%$ vs $15.4 \%$ well/moderately, $P<.001)$. Ki67 was positively correlated with intratumoral expression of programmed death ligand 1, B7-H3, and indoleamine 2,3dioxygenase 1, and elevated stromal expression of lymphocyte activation gene 3 and inducible T-cell co-stimulator. Ki67 expression was inversely associated with intratumoral densities of CD57+ and CD4+ cells. The relationship between Ki67 and checkpoint expression was strongest in stage I tumors. Among patients with stage I, increased Ki67 was independently associated with worse overall survival.

Conclusions: Increased Ki67 expression is associated with biologically aggressive non-small cell lung cancer, enhanced immune checkpoint expression, and reduced intratumoral immune cell infiltration. These findings were strongest in early-stage disease and warrant further investigation in the context of novel therapeutic agents. (J Thorac Cardiovasc Surg 2019;158:911-9)

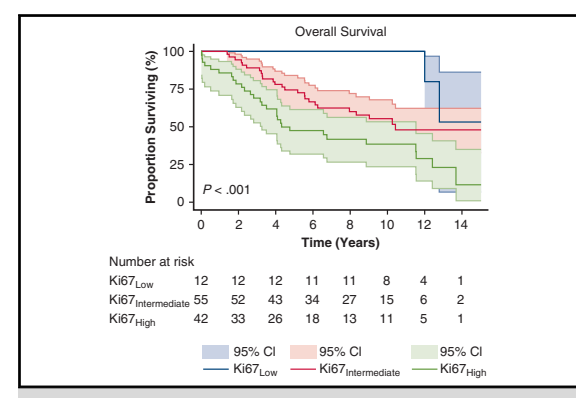

Intratumoral Ki67 expression is associated with poor OS in stage I NSCLC.

\section{Central Message}

Tumor proliferation (Ki67 expression) is positively associated with immune checkpoint expression in stage I NSCLC.

\section{Perspective}

Ki67 is a biomarker of tumor proliferative activity that has been shown to be associated with poor prognosis in NSCLC. By analyzing tumor expression of Ki67, we demonstrate associations between increased tumor proliferation and expression of immune checkpoints. These findings suggest a role for $\mathrm{Ki} 67$ as a marker of an immunosuppressive microenvironment in early-stage NSCLC.

See Commentaries on pages 920 and 922.

\footnotetext{
From the Departments of ${ }^{\mathrm{a}}$ Thoracic and Cardiovascular Surgery, ${ }^{\mathrm{b}}$ Translational Molecular Pathology, and ${ }^{c}$ Bioinformatics and Computational Biology, University of Texas MD Anderson Cancer Center, Houston, Tex.

This work was supported in part by the Cancer Prevention Research Institute of Texas Multi-Investigator Research Awards (RP160668, IIW), National Institutes of Health/National Cancer Institute through the University of Texas Lung Specialized Programs of Research Excellence Grant (P50CA70907, IIW), generous philanthropic donations by the Mason family and anonymous donors, and departmental funding.

The MD Anderson Lung Cancer Immune Microenvironment Working group coauthors are listed at the end of the article.
}

Read at The American Association for Thoracic Surgery Thoracic Summit, New York, New York, October 12-13, 2018.

Received for publication Oct 11, 2018; revisions received April 17, 2019; accepted for publication April 21, 2019; available ahead of print June 22, 2019.

Address for reprints: Mara B. Antonoff, MD, Department of Thoracic and Cardiovascular Surgery, University of Texas MD Anderson Cancer Center, 1515 Holcombe Blvd, Houston, TX 77030 (E-mail: MBAntonoff@mdanderson.org). 0022-5223/ $\$ 36.00$

Copyright (C) 2019 by The American Association for Thoracic Surgery https://doi.org/10.1016/j.jtcvs.2019.04.084 


$$
\begin{aligned}
& \text { Abbreviations and Acronyms } \\
& \begin{array}{ll}
\text { ACA } & =\text { adenocarcinoma } \\
\text { CD } & =\text { cluster of differentiation } \\
\text { CI } & =\text { confidence interval } \\
\text { DFS } & =\text { disease-free survival } \\
\text { FOXP3 } & =\text { forkhead box protein } 3 \\
\text { GZB } & =\text { granzyme B } \\
\text { ICOS } & =\text { inducible T-cell co-stimulator } \\
\text { IDO1 } 1 & =\text { indoleamine } 2,3 \text {-dioxygenase } 1 \\
\text { IQR } & =\text { interquartile range } \\
\text { LAG3 } & =\text { lymphocyte activation gene } 3 \\
\text { MC } & =\text { malignant cell } \\
\text { MST } & =\text { medial survival time } \\
\text { NSCLC } & =\text { non-small cell lung cancer } \\
\text { OS } & =\text { overall survival } \\
\text { PD1 } & =\text { programmed cell death protein } 1 \\
\text { PD-L1 } & =\text { programmed cell death ligand } 1 \\
\text { TME } & =\text { tumor microenvironment }
\end{array}
\end{aligned}
$$

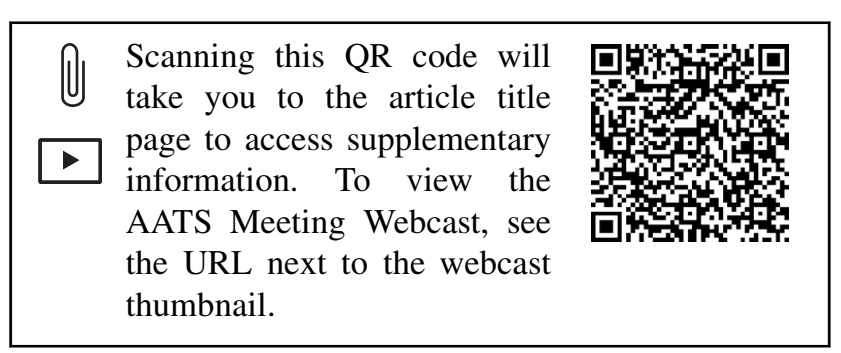

The success of immune checkpoint blockade in the management of non-small cell lung cancer (NSCLC) has brought the importance of the interactions between tumor and immune cells into sharp focus. ${ }^{1-3}$ Development and application of these therapies have been permitted by a growing body of evidence demonstrating that innate and adaptive responses to tumor are characterized by a complex interplay of metabolic signaling and expression of immune checkpoints that can have immunosuppressive or immune-activating effects in the local tumor microenvironment (TME). ${ }^{4}$ As these novel therapies gain wider clinical use in the setting of early and advanced disease, there will be a need for predictors of therapeutic benefit, because not all patients will respond. An enhanced understanding of the interactions between tumor cells and the immune system may be useful for identification of biomarkers of response.

Ki67 is a nuclear protein that has roles in synthesis of ribosomal RNA and organization and maintenance of chromatin structure during mitosis. ${ }^{5-7}$ Tumorigenic properties of Ki67 have been proposed, and it has been further explored as a potential therapeutic target. ${ }^{7-9}$ Although it is detectable throughout the cell cycle and is expressed constitutively at a low level in quiescent cells, its expression is highest during phases characterized by rapid cellular growth., ${ }^{70-12}$ In NSCLC, tumor proliferation has prognostic significance; a recent meta-analysis of 108 studies identified consistent associations between Ki67 expression and poor oncologic outcomes in several settings. ${ }^{13}$

Although the prognostic significance of Ki67 expression in NSCLC has been extensively studied, the relationship between tumor proliferative activity and characteristics of the local immune microenvironment are not well understood. In light of the known relationships among features of the immune microenvironment, post-therapeutic outcomes, and response to immune checkpoint inhibition, an understanding of the degree to which Ki67 reflects an immunologically favorable or unfavorable TME could help guide decisions regarding choice and timing of therapies. ${ }^{4,14,15}$ Moreover, given ongoing investigation into the development and clinical application of therapeutic agents targeting immune checkpoints expressed on both tumor and immune cells, delineation of the heretofore poorly understood relationships between tumor proliferative activity and immunosuppressive features is an incompletely developed and clinically salient line of inquiry. ${ }^{7,10}$ We hypothesized that tumor proliferative activity as quantified by Ki67 would reflect an immunosuppressive microenvironment and that it would, in turn, be associated with poor survival outcomes among chemotherapy-naïve patients undergoing definitive surgical therapy for NSCLC.

\section{MATERIALS AND METHODS \\ Patient Population}

Patients undergoing resection with definitive intent of primary stage I to III NSCLC between 1997 and 2012 and who had pathological Ki67 expression data available were eligible for analysis. Baseline clinicopathologic characteristics were retrospectively queried from a prospectively maintained departmental database. Because neoadjuvant therapy has been shown to be associated with changes in the TME, patients who received neoadjuvant chemotherapy or radiotherapy were excluded. ${ }^{16}$ Tumors were staged using the seventh edition of the American Joint Commission on Cancer staging system. ${ }^{17}$ This retrospective study was approved by the University of Texas MD Anderson Cancer Center's Institutional Review Board with a waiver of informed consent.

\section{Immunohistochemical Staining and Image Analysis}

For quantification of Ki67 and immune checkpoint expression, tissue microarrays were constructed using formalin-fixed, paraffin-embedded tumor blocks using methods that have been described. ${ }^{18}$ Briefly, tissue microarray sections were prepared using three $1.0-\mathrm{mm}$ cores obtained from the center, periphery, and middle of the tumor. An automated staining system (BOND-MAX, Leica Microsystems, Vista, Calif) was used. After scanning at $\times 200$ magnification using the Aperio AT Turbo system (Leica Microsystems), a trained pathologist reviewed scanned images (ImageScope, Leica Microsystems) and created a digital tissue microarray block with the Aperio eSlide Manager (Leica Microsystems). Tumor proliferation was quantified as the percentage of tumor cells expressing Ki67 (Ki-67/clone MIB-1 [M7240], dilution 1:100; Dako, Carpinteria, Calif). Percentage of cells expressing checkpoints that are predominantly 
expressed on malignant cells (MCs) (programmed cell death ligand 1 [PD-L1], B7-H3, B7-H4, and indoleamine 2,3-dioxygenase 1 [IDO1]) were analyzed in the tumor compartment (tumor nests), and cell densities $\left(\right.$ cells $/ \mathrm{mm}^{2}$ ) of those expressed on host tumor-associated immune cells (V-domain suppressor of T-cell activation, tumor necrosis factor receptor superfamily member 4 , inducible T-cell co-stimulator [ICOS], lymphocyte activation gene 3 [LAG3], and T-cell immunoglobulin and mucindomain containing 3 ) were examined in the stromal compartment (stroma tissue between tumor nests) in 184 of 190 cases $(96.8 \%$ ) as previously described. ${ }^{18}$ For a representative subset of tumors $(171,90.0 \%)$, whole tumor sections had been previously used for quantification of tumorassociated immune cell populations expressing cluster of differentiation (CD) 3, CD4, CD8, CD57, granzyme B (GZB), CD45RO, programmed cell death protein 1 (PD1), forkhead box P3 (FOXP3), and CD68 in five $1 \mathrm{~mm}^{2}$ areas in the intratumoral (tumor nests and stroma of tumor) and peritumoral compartments using methods that have been previously published. ${ }^{19}$ Human tonsil tissue was used as a positive (stained with antibody) and negative (not stained) control. Stained slides were scanned and visualized using ScanScope Aperio AT Turbo scanner and ImageScope software (both Leica Microsystems), respectively, and the Aperio Image Toolbox (Leica Microsystems) was used to visualize and analyze imaging data.

\section{Statistical Analysis}

Associations among expression of Ki67, immune checkpoints, and immune cell densities were analyzed using Spearman's rank correlation test (range -1 [perfect negative correlation] to +1 [perfect positive correlation], with $r=0$ indicating no correlation). ${ }^{20}$ To control for multiple comparisons, all pairwise correlations and analyses of marker densities among samples dichotomized by Ki67 expression were evaluated using a false discovery rate-adjusted $P$ value ( $q$ value) ${ }^{21}$ Because family-wise error rate methods are conservative and may lead to missed findings, we chose to use the false discovery rate method to identify as many significant relationships as possible (with the limitation of increased type I error rate) while controlling the rate of false-positive findings. Differences in Ki67 expression between groups were assessed using Mann-Whitney $U$ and Kruskal-Wallis tests. Heat maps were generated to identify relative coexpression of immune checkpoints and patterns of immune cell infiltrates according to the degree of expression of Ki67 in MCs. For the immune checkpoints with which Ki67 was noted to have statistically significant pairwise correlations, the associations were further modeled by fitting a generalized linear model with Gaussian distribution and identity link to account for relevant clinicopathologic characteristics (age, sex, smoking status, histology, differentiation, pathologic stage; final model selection using Akaike information criterion). Overall survival (OS) was defined as the time from surgery to death; patients alive at the end of the study period were censored at the time of last contact. Disease-free survival (DFS) was defined as the time from surgery to disease recurrence or death; patients without a DFS event were censored at the date of last contact. Univariable Cox proportional hazard regressions were performed to analyze relationships between clinicopathologic parameters and Ki67 expression with OS. Variables with a $P$ value less than .20 on univariable analysis were included in the multivariable model; stepwise backwards elimination was then performed until all variables in the final multivariable model met $P$ less than .10 as the final selection criterion. Median follow-up duration was calculated as the median time from surgery to last contact or death. The Kaplan-Meier method was used to estimate survival, and the logrank test was used to analyze differences in time-to-event outcomes between groups. All analyses were performed using SPSS (version 24.0.0; IBM, Armonk, NY) and R (version 3.3.0; http://www.r-project.org). Heat maps were generated using the native Heatmap function for R. Determination of the cutoff values of Ki67 that best discriminated postoperative OS was performed using the FindCut package for R, which determines the optimal number of cutoff points according to the Akaike information
TABLE 1. Baseline clinical, pathologic, and treatment characteristics of the examined cohort

\begin{tabular}{|c|c|}
\hline Variable & N $(\%)$ or median (IQR) \\
\hline Age, median (IQR) (y) & $66.0(60.0-74.0)$ \\
\hline \multicolumn{2}{|l|}{ Sex } \\
\hline Female & $88(46.3)$ \\
\hline Male & $102(53.7)$ \\
\hline \multicolumn{2}{|l|}{ Smoking } \\
\hline Never & $19(10.0)$ \\
\hline Former/current & $171(90.0)$ \\
\hline \multicolumn{2}{|l|}{ Zubrod } \\
\hline 0 & $92(48.4)$ \\
\hline 1 & $97(51.1)$ \\
\hline 2 & $1(0.5)$ \\
\hline \multicolumn{2}{|l|}{ Histology } \\
\hline ACA & $114(60.0)$ \\
\hline $\mathrm{SCC}$ & 72 (37.9) \\
\hline NSCLC NOS & $4(2.1)$ \\
\hline \multicolumn{2}{|l|}{ Differentiation } \\
\hline Well/moderate & $110(57.9)$ \\
\hline Poor & $80(42.1)$ \\
\hline \multicolumn{2}{|l|}{ Extent of resection } \\
\hline Sublobar & $6(3.2)$ \\
\hline Lobectomy/bilobectomy & $170(89.5)$ \\
\hline Pneumonectomy & $14(7.4)$ \\
\hline \multicolumn{2}{|l|}{ Pathologic margin } \\
\hline R0 & $182(95.8)$ \\
\hline $\mathrm{R} 1$ & $7(3.7)$ \\
\hline $\mathrm{R} 2$ & $1(0.5)$ \\
\hline \multicolumn{2}{|l|}{ Pathologic stage } \\
\hline I & $109(57.4)$ \\
\hline II & $48(25.3)$ \\
\hline III & $33(17.4)$ \\
\hline \multicolumn{2}{|l|}{ pT } \\
\hline pT1 & $66(34.7)$ \\
\hline pT2 & $94(49.5)$ \\
\hline pT3 & $23(12.1)$ \\
\hline pT4 & $7(3.7)$ \\
\hline \multicolumn{2}{|l|}{$\mathrm{pN}$} \\
\hline pNO & $127(66.8)$ \\
\hline $\mathrm{pN} 1$ & $38(20.0)$ \\
\hline $\mathrm{pN} 2$ & $25(13.2)$ \\
\hline \multicolumn{2}{|l|}{ Adjuvant therapy } \\
\hline Chemotherapy & $36(18.9)$ \\
\hline Radiotherapy & $17(8.9)$ \\
\hline
\end{tabular}

$I Q R$, Interquartile range; $A C A$, adenocarcinoma; $S C C$, squamous cell carcinoma; NSCLC NOS, non-small cell lung cancer, not otherwise specified.

criterion method and the optimal location of cutoff points according to the likelihood ratio test. ${ }^{22}$

\section{RESULTS}

Patient and Tumor Characteristics

A total of 190 patients were eligible for analysis (Figure E1). Most patients were men (102, 53.7\%), had 


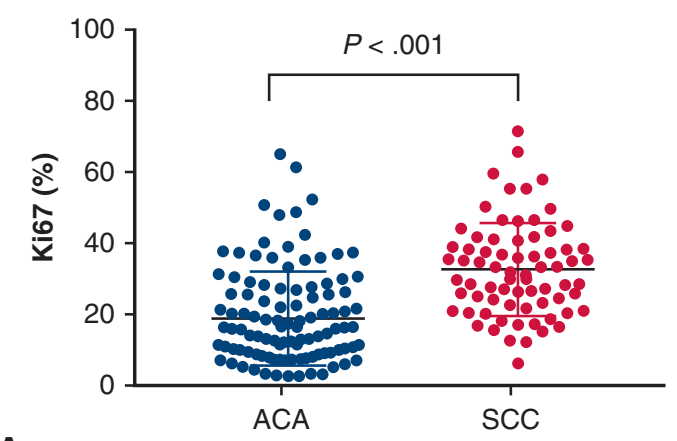

A

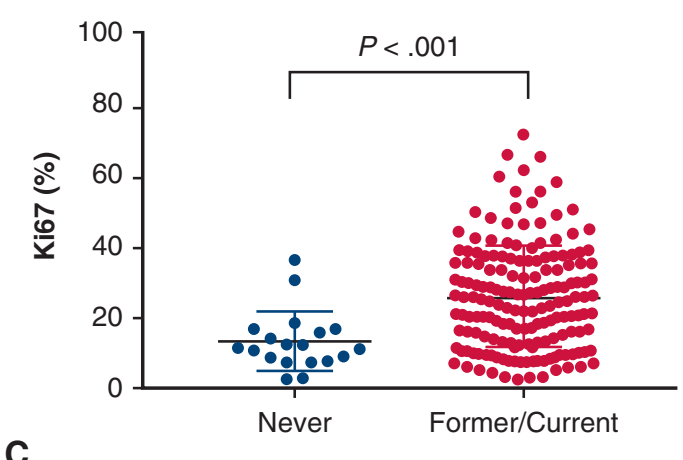

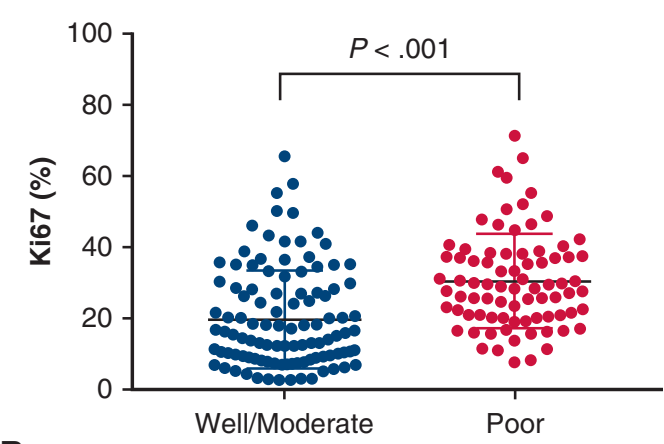

B

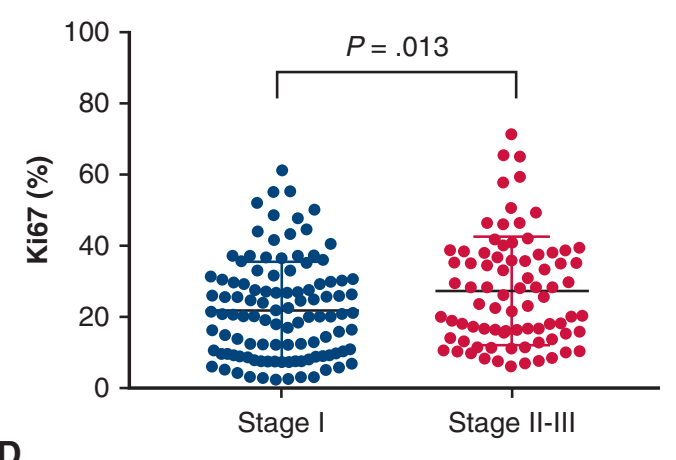

D

FIGURE 1. Tumor expression of Ki67 was noted to be higher in (A) squamous cell carcinoma than ACA, (B) poorly differentiated rather than moderately or well differentiated tumors, (C) ever smokers, and (D) patients with advanced pathological stage. ACA, Adenocarcinoma; SCC, squamous cell carcinoma.

early-stage disease (pathological stage I: 109, 57.4\%), and underwent anatomic lobectomy (170, 89.5\%) (Table 1). A majority of tumors studied were adenocarcinomas (ACAs) $(114,60.0 \%)$ and well or moderately differentiated (110, $57.9 \%)$.

\section{Associations Between Tumor Proliferation and Clinicopathologic Characteristics}

No differences in Ki67 expression were observed between men (median $23.1 \%$ positive tumor cells; interquartile range [IQR], 12.5-34.8) and women (median 21.0\% positive tumor cells [10.6-35.3], $P=.659$ ) (distribution of Ki67 expression for the study cohort provided in Figure E2). Former or current smokers had higher intratumoral expression of Ki67 (median $24.6 \%$ positive tumor cells [13.2-35.9]) than never-smokers (median $11.4 \%$ positive tumor cells [7.7-16.5], $P<.001)$. Ki67 expression was higher in squamous cell carcinoma (median $31.4 \%$ positive tumor cells [22.8-40.2]) than in ACA (median $15.2 \%$ positive tumor cells [9.0-26.4], $P<.001$ ) (Figure 1). Measured expression of Ki67 was highest in stage III tumors (median $28.5 \%$ positive tumor cells [18.7-36.7] vs stages I (median 20.8\% [9.6-30.5]) and II (median 19.2\% [13.1-38.2], $P=.025$ ). Likewise, pathological nodal involvement was associated with higher Ki67 (pN0 median $20.8 \%$ positive tumor cells [9.7-30.5] vs $\mathrm{pN}+$ median $28.3 \%$ [16.5-38.5], $P=.003$ ). Poorly differentiated tumors (median $28.8 \%$ positive tumor cells [20.6-38.0]) were noted to have higher expression of Ki67 than those that were moderately or well differentiated (median $15.4 \%$ positive tumor cells [9.0-28.4], $P<.001$ ). Ki67 expression was positively correlated with pathologic tumor size $(\mathrm{r}=0.191, P=.018)$.

\section{Tumor Proliferation Is Associated With Enhanced Immune Checkpoint Expression on Tumor and Immune Cells in Early-Stage Non-Small Cell Lung Cancer}

Tumor proliferative activity was observed to be strongly correlated with expression of several immune checkpoints in the tumor compartment by MCs, including PD-L1 $(\mathrm{r}=0.287, P<.001)$, B7H3 $(\mathrm{r}=0.235, P=.006)$, and IDO1 ( $\mathrm{r}=0.225, P=.008$ ) (Figure 2, $A$ ). Increased Ki67 expression was also associated with enhanced expression of LAG3 by tumor-associated immune cells in the stromal compartment $(\mathrm{r}=0.245, P=.004)$. Ki67 was weakly associated with increased expression of the costimulatory molecule ICOS ( $\mathrm{r}=0.175, P=.036)$. Tumors characterized by Ki67 expression greater than the observed median were noted to have increased densities of cells expressing the inhibitory checkpoint PD1 in the intratumoral (median 625.8 cells $/ \mathrm{mm}^{2}$ [IQR, 365.8-931.2] vs 464.6 [289.1687.1], $P=.032)$ and peritumoral (1066.7 [714.9-1519.5] vs 875.2 [603.6-1124.1], $P=.043)$ compartments. 


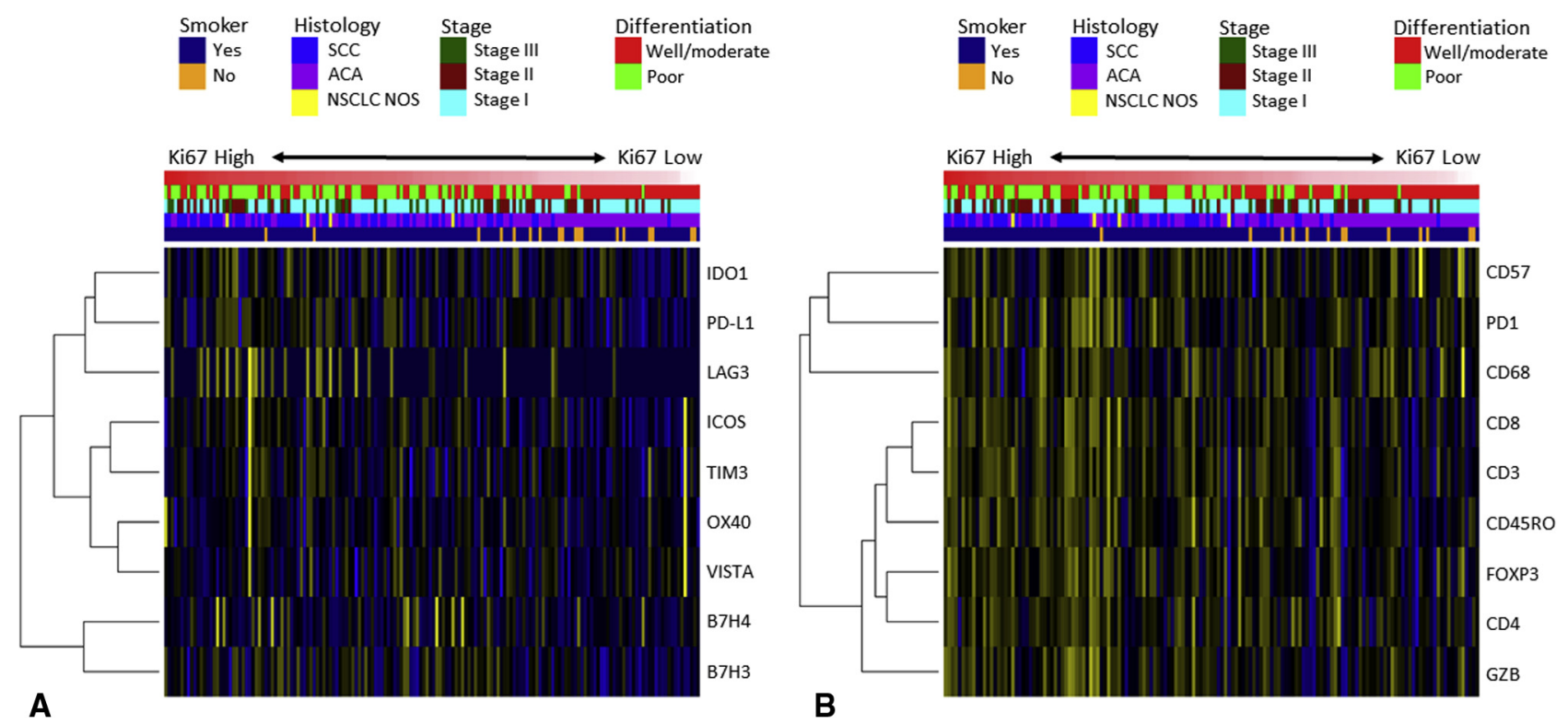

FIGURE 2. Associations between tumor expression of Ki67 and features of the immune microenvironment. A, Elevated Ki67 expression was associated with statistically significant increases in expression of the checkpoint molecules PD-L1, B7H3, and IDO1; however, no clustering of immune checkpoint expression was observed. B, Tumors with high expression of Ki67 were associated with increased peritumoral infiltration by several immune cell populations. In contrast, increased Ki67 expression was associated with a statistically significant decrease in densities of immune cells expressing CD4 and CD57 in the tumor compartment. The cohort was ordered along the $\mathrm{x}$ axis according to decreasing Ki67 expression; the dendrograms on the left $\mathrm{y}$ axis indicate relative similarity or dissimilarity between rows (expression of each individual marker). SCC, Squamous cell carcinoma; ACA, adenocarcinoma; IDOI, indoleamine 2,3-dioxygenase 1; PD-L1, programmed death ligand 1; LAG3, lymphocyte activation gene 3; ICOS, inducible T-cell co-stimulator; TIM3, T-cell immunoglobulin and mucin-domain containing 3; OX40, tumor necrosis factor receptor superfamily, member 4; VISTA, V-domain suppressor of T cell activation; NSCLC NOS, non-small cell lung cancer, not otherwise specified; PD1, programmed cell death protein 1.

Although Ki67 expression was not independently associated with expression of B7H3 or IDO1 after controlling for relevant clinicopathologic characteristics, its expression remained associated with increased tumor expression of PD-L1 $(P=.043)$.

Of note, expression of Ki67 by MCs was inversely correlated with infiltration of the tumor compartment by cells expressing CD4 $(\mathrm{r}=-0.208, P=.015)$ and CD57 $(\mathrm{r}=-0.220, P=.010)$. No association was observed between Ki67 expression and densities of $\mathrm{CD}^{+}$cells in the tumor compartment $(\mathrm{r}=0.125, P=.170)$. In the peritumoral compartment, increased infiltration by tumorassociated immune cells expressing CD3 $(r=0.390$, $P<.001), \mathrm{CD} 4(\mathrm{r}=0.242, P=.008), \mathrm{CD} 8(\mathrm{r}=0.384$, $P<.001)$, CD45RO $(\mathrm{r}=0.321, P<.001)$, FOXP3 $(\mathrm{r}=0.347, P<.001)$, and GZB $(\mathrm{r}=0.285, P=.002)$ was associated with Ki67 expression (Figure 2, B). Upon subgroup analysis after stratification by histology, relationships between Ki67 and checkpoint expression were preserved in ACAs, whereas these associations did not meet statistical significance in squamous cell carcinomas (Tables E1 and E2). Upon subgroup analysis after stratification by pathologic stage, the associations between Ki67 expression and checkpoint expression were present in pathologic stage I tumors but absent in stages II and III
(Table E3), suggesting that the relationship between Ki67 expression and an immunosuppressive microenvironment may be absent in more advanced stages of disease.

\section{Increased Proliferative Index Is Negatively Associated With Survival After Resection of Pathological Stage I Non-Small Cell Lung Cancer}

After a median follow-up time of 70.0 months, there were 121 deaths and 123 DFS events; median survival time (MST) and DFS time for the entire cohort were 78.7 (95\% confidence interval $[\mathrm{CI}], 50.5-106.9)$ months and 62.1 (95\% CI, 37.5-86.7) months, respectively. Because an interaction was observed between Ki67 expression and pathological stage (OS interaction term $P=.004$; DFS interaction term $P=.002$ ) and Ki67 was not associated with survival in advanced stages, the cohort was stratified and further analysis was restricted to patients with pathological stage I disease (109/190; 57 deaths and 58 DFS events; MST 138.3 months, 95\% CI, 104.2-172.4; median DFS time 125.0 months, 95\% CI, 84.0-166.1). The optimal cutoffs to define low-, intermediate-, and high-risk stage I tumors according to postoperative OS were $7.17 \%$ or less (Ki67 ${ }_{\text {Low }} ; 12 / 109$; MST not reached), $7.17 \%$ to $25.73 \%$ (Ki67 Intermediate; 55/109; MST 125.0 months, 95\% CI, not reached), and greater than $25.73 \%\left(\mathrm{Ki}_{\mathrm{High}} ; 42 / 109\right.$; 


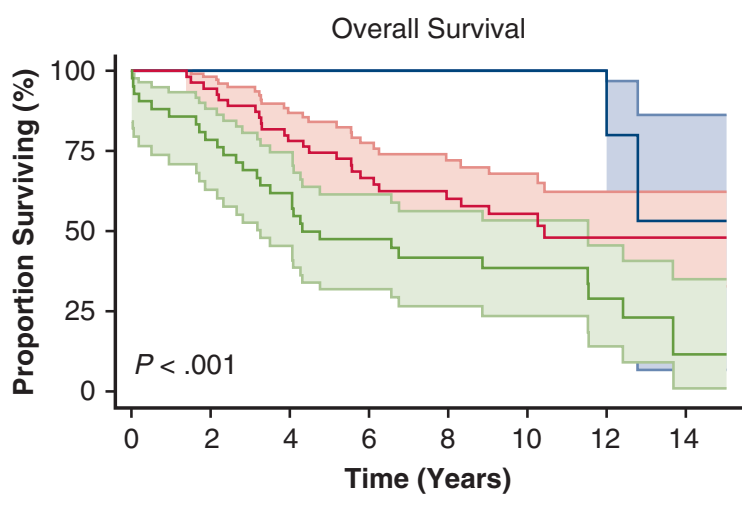

Number at risk

\begin{tabular}{|c|c|c|c|c|c|c|c|}
\hline Ki67 Low & 12 & 12 & 12 & 11 & 11 & 8 & 4 \\
\hline Ki67 Intermediate & 55 & 52 & 43 & 34 & 27 & 15 & 6 \\
\hline Ki67 ${ }_{\text {High }}$ & 42 & 33 & 26 & 18 & 13 & 11 & 5 \\
\hline
\end{tabular}

FIGURE 3. Intratumoral expression of Ki67 (Ki67 low: $\leq 7.17 \%$; Ki67 intermediate: $7.17 \%-25.73 \%$; Ki67 high: $>25.73 \%$ ) was associated with worse OS among patients with pathological stage I tumors. $C I$, Confidence interval.

MST 51.7 months, 95\% CI, 14.9-88.5 months), respectively (log-rank $P<.001$ ) (Figure 3 ). Post hoc analysis identified expression of PD-L1 (Ki67 $7_{\text {High }}$ median $36.7 \%$ of tumor cells PD-L1 ${ }^{+}$[IQR, 17.1-88.1] vs Ki67 ${ }_{\text {Low }} 16.3 \%$ [8.8-19.1] and Ki67 Intermediate $22.8 \% \quad$ [12.4-54.3], $P=.002)$ and IDO1 (Ki67 $7_{\mathrm{High}} 6.6[\mathrm{IQR}, 3.0-21.0]$, Ki67 ${ }_{\text {Low }}$ 2.1 [1.0-4.6], Ki67 Intermediate 4.5 [1.8-13.5], $P=.027$ ) to be highest among $\mathrm{Ki} 7_{\mathrm{High}}$ tumors. Likewise, densities of tumor-associated immune cells expressing the inhibitory checkpoint PD1 were highest in Ki67 ${ }_{\text {High }}$ tumors in both intratumoral (691.5 [IQR, 386.8-1100.1] cells $/ \mathrm{mm}^{2}$ vs Ki67 Low 300.2 [202.6-455.1] and Ki67 Intermediate 521.4 [356.9-764.2], $P=.005)$ and peritumoral $\left(\mathrm{Ki}_{\mathrm{High}}\right.$ 1118.4 [746.6-1715.4], Ki67 Low 910.4 [724.9-1103.3], Ki67 Intermediate 815.6 [627.3-1185.8], $P=.034$ ) compartments. On multivariable analysis, Ki67 expression remained independently associated with an increased hazard of death (Ki67 Intermediate HR 4.33, 95\% CI, 1.00-18.67; Ki67 ${ }_{\text {High }}$ HR 8.23, 95\% CI, 1.91-35.41) (Tables 2 and Table E4) and DFS events (Tables E5 and E6) (Video 1).

\section{DISCUSSION}

In this analysis of chemotherapy-naïve patients undergoing definitive surgical therapy for NSCLC, we identify associations between high tumor proliferative activity as quantified by Ki67 and enhanced immune checkpoint expression on both tumor cells and immune cells within the local TME, particularly among stage I tumors. Tumors characterized by high proliferative activity were associated with reduced intratumoral infiltration by cells expressing markers for helper T lymphocytes (CD4) and natural killer cells (CD57), although they were also marked by increased peritumoral inflammatory infiltrates. Finally, high Ki67 expression identified a subgroup of patients with pathological stage I disease who were at a markedly increased hazard of death after resection. To the authors' knowledge, the present study represents the first characterization of the relationship between tumor proliferation and an immunosuppressive TME in NSCLC.

The ability of MCs to evade immunosurveillance plays a crucial role in the development and progression of tumors. Critical to this process is the suppression of immune responses by expression of immune checkpoints that can diminish host immune cell activity and induce lymphocyte death. These checkpoints may act via independent pathways, and their degree of coexpression may be a function of molecular subtype. ${ }^{18,23,24}$ Although the PD-L1/PD1 axis currently tends to be the ligand-receptor pair of greatest current scrutiny, expression of IDO1 (an enzyme involved in tryptophan catabolism), the transmembrane immunoregulatory protein $\mathrm{B} 7 \mathrm{H} 3$, and the lymphocyte-inactivating LAG3 have been shown to have prognostic significance in NSCLC. ${ }^{24-27}$ Exploration of therapies targeting these checkpoints is ongoing. ${ }^{28,29}$ In the present study, by analyzing tumor expression of Ki67 and several immune checkpoints, we highlight associations between an immunosuppressive local microenvironment and rapid tumor proliferation. Because the efficacy of cytotoxic therapy and immunotherapy are enhanced by tumor growth and checkpoint expression, respectively, we propose that pretreatment expression of Ki67 be further explored as a predictive biomarker among patients with NSCLC receiving checkpoint inhibitors, cytotoxic agents, or novel combinations thereof. ${ }^{30,31}$

In the present study, our observations of an association between tumor proliferation and an immunosuppressive microenvironment are supported by the inverse associations between Ki67 and intratumoral infiltration by cells expressing CD4, a marker for helper T lymphocytes, and CD57, a marker of natural killer cells. In contrast, tumors characterized by high expression of Ki67 were observed to have a highly inflamed peritumoral compartment marked by increased densities of a variety of immune cell populations expressing CD3, CD4, CD8, CD45RO, FOXP3, and GZB. Likewise, tumor-associated immune cell expression of the T-cell stimulatory factor ICOS was enhanced in highly proliferative tumors. Taken together, these findings suggest an appropriate lymphocytic response to tumor growth activity in the peritumoral compartment with a contradictory inability of immune cells to infiltrate the intratumoral compartment and tumor nests. Given the proposed importance of spatial interactions between malignant and immune cells, this compartment-specific difference in relative immune cell infiltration warrants further investigation. ${ }^{32}$ 
TABLE 2. Univariable and multivariable analysis of factors associated with overall survival among patients with pathological stage I tumors $(\mathbf{n}=109)$

\begin{tabular}{|c|c|c|c|c|c|}
\hline \multirow[b]{2}{*}{ Variable } & \multirow[b]{2}{*}{$\mathbf{N}(\%)$} & \multicolumn{2}{|c|}{ Univariable } & \multicolumn{2}{|c|}{ Multivariable } \\
\hline & & HR $(95 \%$ CI $)$ & $P$ & HR $(95 \%$ CI $)$ & $P$ \\
\hline \multicolumn{6}{|l|}{ Age } \\
\hline$<65 \mathrm{y}$ & $45(41.3)$ & Reference & & Reference & \\
\hline$\geq 65 \mathrm{y}$ & $64(58.7)$ & $2.32(1.30-4.12)$ & .004 & $2.99(1.55-5.75)$ & .001 \\
\hline \multicolumn{6}{|l|}{ Sex } \\
\hline Female & $63(57.8)$ & Reference & & & \\
\hline Male & $46(42.2)$ & $1.45(0.86-2.45)$ & .164 & & \\
\hline \multicolumn{6}{|l|}{ Smoker } \\
\hline Never & $14(12.8)$ & Reference & & & \\
\hline Ever & $95(87.2)$ & $1.53(0.65-3.59)$ & .328 & & \\
\hline \multicolumn{6}{|l|}{ Zubrod } \\
\hline 0 & $61(56.0)$ & Reference & & & \\
\hline 1 & $48(44.0)$ & $0.73(0.43-1.23)$ & .237 & & \\
\hline \multicolumn{6}{|l|}{ FEV1 } \\
\hline$>70 \%$ Predicted & $82(75.2)$ & Reference & & & \\
\hline$\leq 70 \%$ Predicted & $27(24.8)$ & $1.72(0.97-3.04)$ & .065 & & \\
\hline Tumor size $(\mathrm{cm})$ & $\mathrm{n} / \mathrm{a}$ & $1.15(0.94-1.42)$ & .184 & $1.26(1.00-1.60)$ & .051 \\
\hline \multicolumn{6}{|l|}{ Differentiation } \\
\hline Well/moderate & $69(63.3)$ & Reference & & & \\
\hline Poor & $40(36.7)$ & $1.80(1.06-3.06)$ & .029 & & \\
\hline \multicolumn{6}{|l|}{ Histology } \\
\hline ACA & $73(67.0)$ & Reference & & & \\
\hline SCC & $33(30.3)$ & $2.15(1.26-3.68)$ & .005 & & \\
\hline NSCLC NOS & $3(2.8)$ & $1.60(0.38-6.69)$ & .522 & & \\
\hline \multicolumn{6}{|l|}{ Extent of resection } \\
\hline Lobectomy/bilobectomy & $105(96.3)$ & Reference & & Reference & \\
\hline Sublobar & $4(3.7)$ & $7.58(2.57-22.36)$ & $<.001$ & $5.00(1.66-15.06)$ & .004 \\
\hline \multicolumn{6}{|l|}{ Margin } \\
\hline R0 & $107(98.2)$ & Reference & & & \\
\hline R1 & $2(1.8)$ & $2.71(0.66-11.18)$ & .169 & & \\
\hline \multicolumn{6}{|l|}{ Ki67 expression* } \\
\hline Low & $12(11.0)$ & Reference & & Reference & \\
\hline Intermediate & $55(50.5)$ & $4.33(1.02-18.41)$ & .047 & $4.33(1.00-18.67)$ & .050 \\
\hline High & $42(38.5)$ & $8.22(1.96-34.52)$ & .004 & $8.23(1.91-35.41)$ & .005 \\
\hline \multicolumn{6}{|l|}{ Adjuvant chemotherapy } \\
\hline None & $91(83.5)$ & Reference & & Reference & \\
\hline Chemotherapy & $18(16.5)$ & $0.39(0.15-0.98)$ & .044 & $0.42(0.16-1.07)$ & .070 \\
\hline
\end{tabular}

HR, Hazard ratio; $C I$, confidence interval; FEVI, forced expiratory volume in 1 second; ACA, adenocarcinoma; SCC, squamous cell carcinoma; $N S C L C N O S$, non-small cell lung cancer, not otherwise specified. *Low expression: Ki67 $\leq 7.17 \%$; Intermediate expression: Ki67 7.17\%-25.73\%; High expression: Ki67 $>25.73 \%$.

In this cohort of chemotherapy-naïve patients with resected NSCLC, the prognostic effect of Ki67 expression was moderated by pathological stage such that it retained prognostic significance only in patients with stage I disease. The observation that Ki67 was more closely related to an immunosuppressive microenvironment in stage I disease than in more advanced stages provides a possible mechanistic explanation for the differential prognostic significance that similarly varied according to pathologic stage. In concert with this observation, several previous analyses have identified associations between tumor proliferation and postoperative survival in patients with stage I NSCLC. ${ }^{13}$ Further, by trichotomizing our institutional cohort of patients with stage I disease, we identified a subgroup defined by an easily applicable cutoff (Ki67 expression in $\sim 25 \%$ of tumor cells) with postoperative survival approaching that historically observed in stage II disease. ${ }^{33}$ Whether intratumoral Ki67 expression defines a subset of stage I tumors at sufficiently high risk of treatment failure that the use of adjuvant therapy is justified is a subject that warrants further investigation. 
Tumor Cellular Proliferation Is Associated with Enhanced Immune Checkpoint Expression in Resected Non-Small Cell Lung Cancer

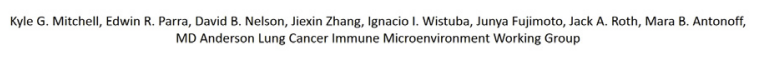

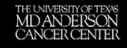
sis

VIDEO 1. A summary of the key findings of the study and their relevance. Video available at: https://www.jtcvs.org/article/S0022-5223(19)31015-3/ fulltext.

\section{Study Limitations}

Despite the limitations imposed on this study by its retrospective nature, the long follow-up period allowed for discrimination of patients with relatively low-risk disease into 3 distinct risk strata. Although our findings regarding the associations between tumor proliferation and checkpoint expression are intriguing in the possibility of their application to the context of immune checkpoint inhibitors, we restricted our analysis to patients who had not received neoadjuvant therapy. It is unclear what impact the exposure to previous therapies and potential clonal selection might have on these relationships. Further study is needed to clarify whether these findings are preserved in the context of alterations in tumor biology that are associated with disease progression from the locoregional to the advanced setting. Further, because the cohort was defined by the availability of Ki67 expression data, a small subset lacked other immunohistochemistry data, and the study cohort reflects only a small subgroup of all patients with NSCLC undergoing resection at our institution during the study period. Finally, an exploratory analysis of tumors stratified by histology demonstrated that these associations were not present in squamous cell carcinomas; this observation warrants further investigation. As biomarkers are developed for the purposes of prediction and prognostication in NSCLC, it may well be the case that a signature of several markers tailored to histopathologic subtypes may be the optimal approach. No association was observed between expression of Ki67 and immune checkpoints in stage II and III tumors after stratification according to pathologic stage. Further analyses of trials using novel therapies in the neoadjuvant and adjuvant settings are needed to define the clinical significance of this apparent stage-specific relationship.

\section{CONCLUSIONS}

We identified associations between tumor proliferative activity as quantified by tumor expression of Ki67 and features associated with an aggressive tumor biology.
Additionally, rapidly proliferating tumors were associated with a high degree of stromal inflammatory response but reduced infiltration of several cell populations in the tumor compartment. These results highlight the need for further investigation in the prospective setting to identify whether pretreatment quantification of Ki67 can be used as a predictive marker for response to novel therapies.

\section{Webcast}

You can watch a Webcast of this AATS meeting presentation by going to: https://aats.blob.core.windows.net/ media/ITSOS18/GS-13-0845-0900-Mitchell-720p.mp4.

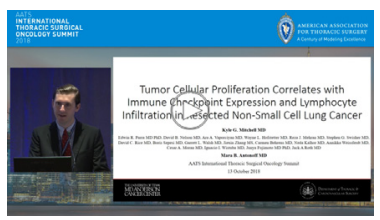

\section{Conflict of Interest Statement}

Roth discloses unrelated relationships with Genprex (equity, consulting) and Varian (grant support). All other authors have nothing to disclose with regard to commercial support.

The MD Anderson Lung Cancer Immune Microenvironment Working Group coauthors include Erin M. Corsini, MD, Ara A. Vaporciyan, MD, Wayne L. Hofstetter, MD, Reza J. Mehran, MD, Stephen G. Swisher, MD, David C. Rice, MD, Boris Sepesi, MD, Garrett L. Walsh, Carmen Behrens, MD, Neda Kalhor, MD, Annikka Weissferdt, MD, DrMed, Cesar A. Moran, MD, and J. Jack Lee, PhD, MS, DDS.

\section{References}

1. Borghaei H, Paz-Ares L, Horn L, Spigel DR, Steins M, Ready NE, et al. Nivolumab versus docetaxel in advanced nonsquamous non-small-cell lung cancer. $N$ Engl J Med. 2015;373:1627-39.

2. Brahmer J, Reckamp KL, Baas P, Crino L, Eberhardt WE, Pddubskaya E, et al. Nivolumab versus docetaxel in advanced squamous-cell non-small-cell lung cancer. N Engl J Med. 2015;373:123-35.

3. Forde PM, Chaft JE, Smith KN, Anagnostou V, Cottrell TR, Hellmann MD, et al. Neoadjuvant PD-1 blockade in resectable lung cancer. N Engl J Med. 2018;378: 1976-86.

4. Sharma P, Hu-Lieskovan S, Wargo JA, Ribas A. Primary, adaptive, and acquired resistance to cancer immunotherapy. Cell. 2017;168:707-23.

5. Cuylen S, Blaukopf C, Politi AZ, Muller-Reichert T, Neumann B, Poser I, et al. Ki-67 acts as a biological surfactant to disperse mitotic chromosomes. Nature. 2016;535:308.

6. Rahmanzadeh R, Hüttmann G, Gerdes J, Scholzen T. Chromophore-assisted light inactivation of pKi-67 leads to inhibition of ribosomal RNA synthesis. Cell Prolif. 2007;40:422-30.

7. Sobecki M, Mrouj K, Colinge J, Gerbe F, Hay P, Krasinska L, et al. Cell-cycle regulation accounts for variability in Ki-67 expression levels. Cancer Res. 2017;77:2722-34.

8. Zheng JN, Ma TX, Cao JY, Sun XQ, Chen JC, Li W, et al. Knockdown of Ki-67 by small interfering RNA leads to inhibition of proliferation and induction of apoptosis in human renal carcinoma cells. Life Sci. 2006;78:724-9.

9. Lee JJ, Liu D, Lee JS, Kurie JM, Khuri FR, Ibarguen H, et al. Long-term impact of smoking on lung epithelial proliferation in current and former smokers. J Natl Cancer Inst. 2001;93:1081-8. 
10. Sun X, Kaufman PD. Ki-67: more than a proliferation marker. Chromosoma. 2018;127:175-86

11. Bullwinkel J, Baron-Luhr B, Ludemann A, Wohlenberg C, Gerdes J, Scholzen T. Ki-67 protein is associated with ribosomal RNA transcription in quiescent and proliferating cells. J Cell Physiol. 2006;206:624-35.

12. Miller I, Min M, Yang C, Tian C, Gookin S, Carter D, et al. Ki67 is a graded rather than a binary marker of proliferation versus quiescence. Cell Rep. 2018;24: 1105-12.e1105.

13. Wei DM, Chen WJ, Meng RM, Zhao N, Zhang XY, Liao DY, et al. Augmented expression of Ki-67 is correlated with clinicopathological characteristics and prognosis for lung cancer patients: an up-dated systematic review and metaanalysis with 108 studies and 14,732 patients. Respir Res. 2018;19:150.

14. Chen L, Diao L, Yang Y, Yi X, Rodriguez BL, Li Y, et al. CD38-mediated immunosuppression as a mechanism of tumor cell escape from PD-1/PD-L1 blockade. Cancer Discov. 2018;8:1156-75.

15. Soo RA, Chen Z, Yan Teng RS, Tan HL, Iacopetta B, Tai BC, et al. Prognostic significance of immune cells in non-small cell lung cancer: meta-analysis. Oncotarget. 2018;9:24801-20.

16. Parra ER, Villalobos P, Behrens C, Jiang M, Pataer A, Swisher SG, et al. Effect of neoadjuvant chemotherapy on the immune microenvironment in non-small cell lung carcinomas as determined by multiplex immunofluorescence and image analysis approaches. J Immunother Cancer. 2018;6:48.

17. Edge S, Byrd DR, Compton CC, Fritz AG, Greene F, Trotti A III, eds. AJCC Cancer Staging Handbook. 7th ed. New York: Springer; 2010.

18. Parra ER, Villalobos P, Zhang J, Behrens C, Mino B, Swisher SG, et al. Immunohistochemical and image analysis-based study shows that several immune checkpoints are co-expressed in non-small cell lung carcinoma tumors. J Thorac Oncol. 2018;13:779-91.

19. Parra ER, Behrens C, Rodriguez-Canales J, Lin H, Mino B, Blando J, et al. Image analysis-based assessment of PD-L1 and tumor-associated immune cells density supports distinct intratumoral microenvironment groups in non-small cell lung carcinoma patients. Clin Cancer Res. 2016;22:6278-89.

20. Spearman C. The proof and measurement of association between two things. Am J Psychol. 1904;15:72-101.

21. Benjamini Y, Hochberg Y. Controlling the false discovery rate: a practical and powerful approach to multiple testing. J R Stat Soc Ser B Stat Methodol. 1995; 57:289-300.

22. Chang C, Hsieh M-K, Chang W-Y, Chiang AJ, Chen J. Determining the optimal number and location of cutoff points with application to data of cervical cancer. PLoS One. 2017;12:e0176231.
23. Kadara H, Choi M, Zhang J, Parra ER, Rodriguez-Canales J, Gaffney SG, et al Whole-exome sequencing and immune profiling of early-stage lung adenocarcinoma with fully annotated clinical follow-up. Ann Oncol. 2017;28:75-82.

24. Schalper KA, Carvajal-Hausdorf D, McLaughlin J, Altan M, Velcheti V, Gaule P et al. Differential expression and significance of PD-L1, IDO-1, and B7-H4 in human lung cancer. Clin Cancer Res. 2017;23:370-8.

25. Altan M, Pelekanou V, Schalper KA, Toki M, Gaule P, Syrigos K, et al. B7-H3 Expression in NSCLC and its association with B7-H4, PD-L1 and tumorinfiltrating lymphocytes. Clin Cancer Res. 2017;23:5202-9.

26. He Y, Yu H, Rozeboom L, Rivard CJ, Ellison K, Dziadziusko R, et al. LAG-3 protein expression in non-small cell lung cancer and its relationship with PD-1/PD L1 and tumor-infiltrating lymphocytes. J Thorac Oncol. 2017;12:814-23.

27. Zou W, Chen L. Inhibitory B7-family molecules in the tumour microenvironment. Nat Rev Immunol. 2008;8:467.

28. Loo D, Alderson RF, Chen FZ, Huang L, Zhang W, Gorlatov S, et al. Development of an Fc-enhanced anti-B7-H3 monoclonal antibody with potent antitumor activity. Clin Cancer Res. 2012;18:3834-45.

29. Spranger S, Koblish HK, Horton B, Scherle PA, Newton R, Gajewski TF. Mechanism of tumor rejection with doublets of CTLA-4, PD-1/PD-L1, or IDO blockade involves restored IL-2 production and proliferation of CD8(+) T cells directly within the tumor microenvironment. J Immunother Cancer. 2014;2:3.

30. Rizvi H, Sanchez-Vega F, La K, Chatila W, Jonsson P, Halpenny D, et al. Molecular determinants of response to anti-programmed cell death (PD)-1 and antiprogrammed death-ligand 1 (PD-L1) blockade in patients with non-small-cell lung cancer profiled with targeted next-generation sequencing. J Clin Oncol. 2018;36:633-41.

31. Denkert C, Loibl S, Müller BM, Eidtmann H, Schmitt WD, Eiermann W, et al Ki67 levels as predictive and prognostic parameters in pretherapeutic breast cancer core biopsies: a translational investigation in the neoadjuvant GeparTrio trial Ann Oncol. 2013;24:2786-93.

32. Barua S, Fang P, Sharma A, Fujimoto J, Wistuba I, Rao AUK, et al. Spatial interaction of tumor cells and regulatory T cells correlates with survival in non-small cell lung cancer. Lung Cancer. 2018;117:73-9.

33. Yang L, Wang S, Zhou Y, Lai S, Xiao G, Gazdar A, et al. Evaluation of the 7(th and 8(th) editions of the AJCC/UICC TNM staging systems for lung cancer in a large North American cohort. Oncotarget. 2017;8:66784-95.

Key Words: non-small cell lung cancer, immune microenvironment, immune checkpoints, Ki67 


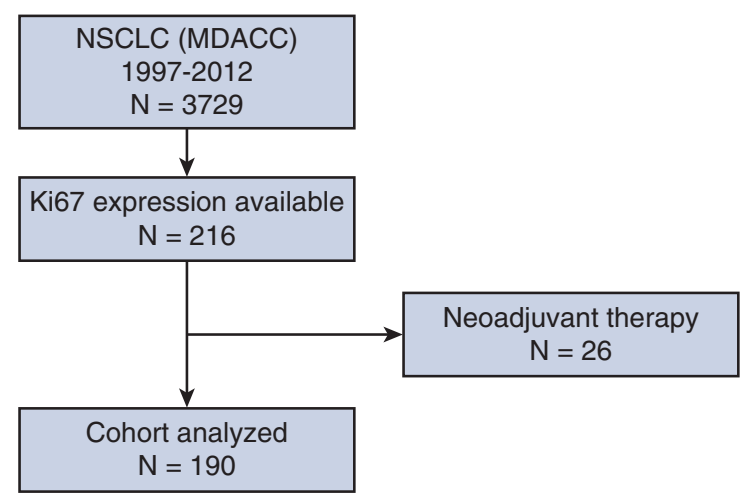

FIGURE E1. Consolidated Standards of Reporting Trials diagram depicting selection of eligible patients. MDACC, MD Anderson Cancer Center; $N S C L C$, non-small cell lung cancer.

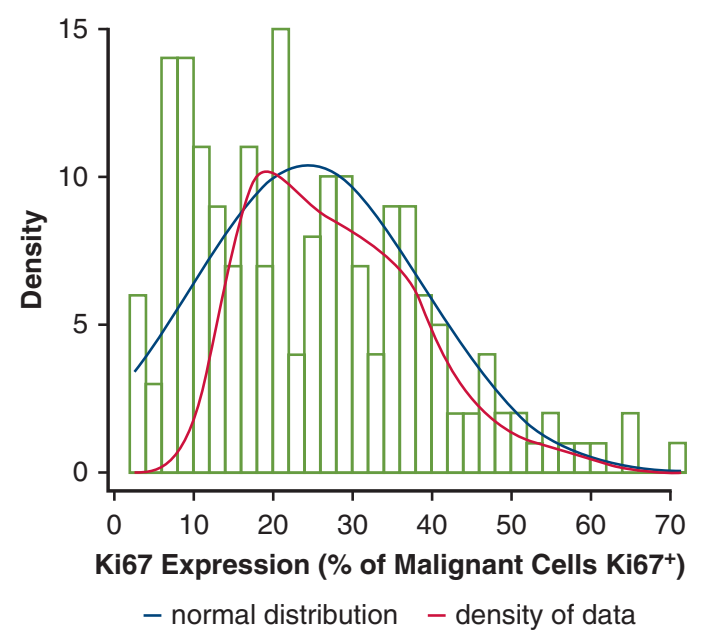

A

FIGURE E2. Distribution of Ki67 among the study cohort depicted by (A) histogram and density function and (B) quantile plot.

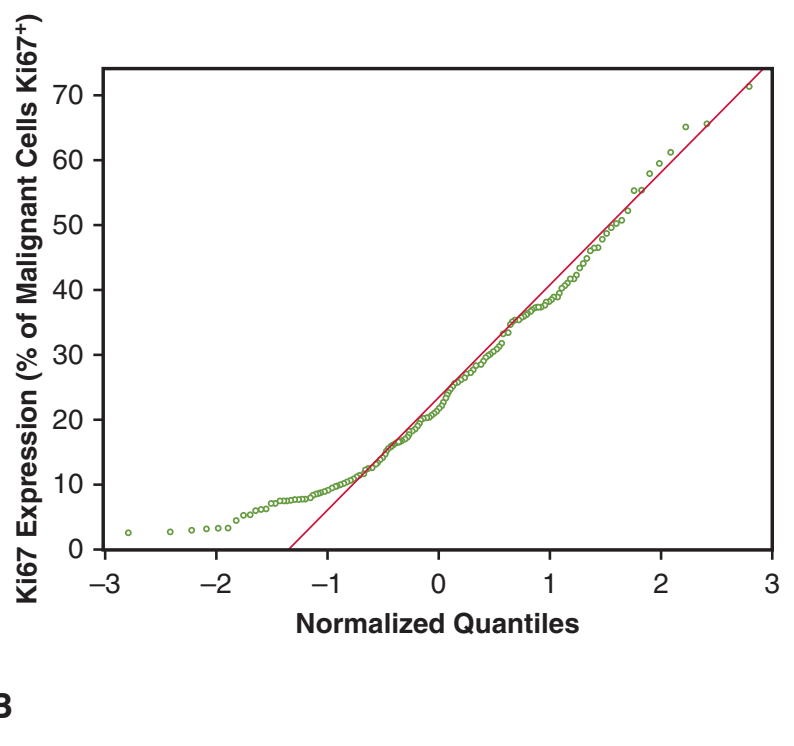


TABLE E1. Associations between tumor expression of Ki67 and expression of immune checkpoints among patients with adenocarcinoma and squamous cell carcinoma

\begin{tabular}{|c|c|c|}
\hline \multicolumn{3}{|c|}{ Adenocarcinoma } \\
\hline Variable & $\mathbf{r}$ & FDR-corrected $P$ \\
\hline $\mathrm{PD} 1_{\text {Intratumoral }}$ & 0.218 & .060 \\
\hline $\mathrm{PD} 1_{\text {Peritumoral }}$ & 0.149 & .225 \\
\hline PD-L1 & 0.410 & $<.001$ \\
\hline B7H3 & 0.237 & .045 \\
\hline B7H4 & -0.115 & .324 \\
\hline IDO1 & 0.272 & .028 \\
\hline VISTA & 0.100 & .384 \\
\hline LAG3 & 0.292 & .016 \\
\hline TIM3 & 0.190 & .089 \\
\hline ICOS & 0.195 & .085 \\
\hline OX40 & 0.218 & .059 \\
\hline \multicolumn{3}{|c|}{ Squamous cell carcinoma } \\
\hline Variable & $\mathbf{r}$ & FDR-corrected $P$ \\
\hline $\mathrm{PD} 1_{\text {Intratumoral }}$ & -0.124 & .705 \\
\hline PD1 $1_{\text {Peritumoral }}$ & 0.041 & .927 \\
\hline PD-L1 & 0.080 & .802 \\
\hline B7H3 & -0.103 & .749 \\
\hline B7H4 & -0.055 & .885 \\
\hline IDO1 & 0.251 & .395 \\
\hline VISTA & -0.138 & .655 \\
\hline LAG3 & 0.142 & .655 \\
\hline TIM3 & -0.102 & .749 \\
\hline ICOS & -0.139 & .655 \\
\hline OX40 & -0.006 & .962 \\
\hline
\end{tabular}

$F D R$, False discovery rate; $P D 1$, programmed cell death protein 1; $P D-L 1$, programmed cell death ligand 1; IDOI, indoleamine 2,3-dioxygenase 1; VISTA, V-domain suppressor of T-cell activation; LAG3, lymphocyte activation gene 3; TIM3, T-cell immunoglobulin and mucin-domain containing 3; ICOS, inducible T-cell co-stimulator; $O X 40$, tumor necrosis factor receptor superfamily, member 4 . 
TABLE E2. Associations between tumor expression of Ki67 and expression of immune checkpoints among patients with pathologic stage $I$ adenocarcinoma and squamous cell carcinoma

\begin{tabular}{|c|c|c|}
\hline \multicolumn{3}{|c|}{ Adenocarcinoma } \\
\hline Variable & $\mathbf{r}$ & $\overline{F D R-c o r r e c t e d ~} P$ \\
\hline $\mathrm{PD} 1_{\text {Intratumoral }}$ & 0.266 & .043 \\
\hline PD1 $1_{\text {Peritumoral }}$ & 0.130 & .422 \\
\hline PD-L1 & 0.493 & $<.001$ \\
\hline В7H3 & 0.338 & .019 \\
\hline B7H4 & -0.189 & .179 \\
\hline IDO1 & 0.298 & .041 \\
\hline VISTA & 0.156 & .2700 \\
\hline LAG3 & 0.345 & .016 \\
\hline TIM3 & 0.282 & .043 \\
\hline ICOS & 0.254 & .054 \\
\hline OX40 & 0.276 & .043 \\
\hline \multicolumn{3}{|c|}{ Squamous cell carcinoma } \\
\hline Variable & $\mathbf{r}$ & FDR-corrected $P$ \\
\hline $\mathrm{PD} 1_{\text {Intratumoral }}$ & 0.326 & .499 \\
\hline PD1 $1_{\text {Peritumoral }}$ & 0.065 & .879 \\
\hline PD-L1 & 0.046 & .879 \\
\hline B7H3 & -0.064 & .879 \\
\hline B7H4 & -0.055 & .879 \\
\hline IDO1 & 0.401 & .499 \\
\hline VISTA & -0.276 & .499 \\
\hline LAG3 & 0.042 & .879 \\
\hline TIM3 & -0.081 & .879 \\
\hline ICOS & -0.276 & .499 \\
\hline OX40 & -0.079 & .879 \\
\hline
\end{tabular}

$\overline{F D R}$, False discovery rate; $P D 1$, programmed cell death protein 1; $P D-L 1$, programmed cell death ligand 1; IDOI, indoleamine 2,3-dioxygenase 1; VISTA, V-domain suppressor of T-cell activation; LAG3, lymphocyte activation gene 3; TIM3, T-cell immunoglobulin and mucin-domain containing 3; ICOS, inducible T-cell co-stimulator; OX40, tumor necrosis factor receptor superfamily, member 4.
TABLE E3. Associations between tumor expression of Ki67 and expression of immune checkpoints among patients with pathologic stage I $(n=109)$ and stages II/III $(n=81)$ non-small cell lung cancer

\begin{tabular}{|c|c|c|}
\hline \multicolumn{3}{|c|}{ Stage I } \\
\hline Variable & $\mathbf{r}$ & FDR-corrected $P$ \\
\hline $\mathrm{PD} 1_{\text {Intratumoral }}$ & 0.151 & .226 \\
\hline $\mathrm{PD} 1_{\text {Peritumoral }}$ & 0.162 & .225 \\
\hline PD-L1 & 0.349 & .002 \\
\hline В7H3 & 0.320 & .004 \\
\hline B7H4 & 0.025 & .868 \\
\hline IDO1 & 0.276 & .016 \\
\hline VISTA & -0.001 & .993 \\
\hline LAG3 & 0.253 & .025 \\
\hline TIM3 & 0.117 & .337 \\
\hline ICOS & 0.150 & .225 \\
\hline OX40 & 0.056 & .687 \\
\hline \multicolumn{3}{|c|}{ Stage II/III } \\
\hline Variable & $\mathbf{r}$ & FDR-corrected $P$ \\
\hline $\mathrm{PD} 1_{\text {Intratumoral }}$ & 0.067 & .643 \\
\hline PD1 $1_{\text {Peritumoral }}$ & 0.145 & .468 \\
\hline PD-L1 & 0.212 & .272 \\
\hline В7H3 & 0.092 & .553 \\
\hline B7H4 & -0.010 & .935 \\
\hline IDO1 & 0.234 & .272 \\
\hline VISTA & 0.018 & .909 \\
\hline LAG3 & 0.224 & .272 \\
\hline TIM3 & 0.079 & .603 \\
\hline ICOS & 0.262 & .272 \\
\hline OX40 & 0.178 & .325 \\
\hline
\end{tabular}

$\overline{F D R}$, False discovery rate; $P D 1$, programmed cell death protein 1; PD-L1, programmed cell death ligand 1; IDOI, indoleamine 2,3-dioxygenase 1; VISTA, V-domain suppressor of T-cell activation; LAG3, lymphocyte activation gene 3; TIM3, T-cell immunoglobulin and mucin-domain containing 3; ICOS, inducible T-cell co-stimulator; OX40, tumor necrosis factor receptor superfamily, member 4. 
TABLE E4. Univariable and multivariable analysis of factors associated with overall survival among patients with pathological stage I tumors, with inclusion of all clinically relevant variables without elimination $(\mathbf{n}=109)$

\begin{tabular}{|c|c|c|c|c|c|}
\hline \multirow[b]{2}{*}{ Variable } & \multirow[b]{2}{*}{$\mathbf{N}(\%)$} & \multicolumn{2}{|c|}{ Univariable } & \multicolumn{2}{|c|}{ Multivariable } \\
\hline & & HR $(95 \%$ CI $)$ & $P$ & HR $(95 \%$ CI $)$ & $P$ \\
\hline \multicolumn{6}{|l|}{ Age } \\
\hline$<65 \mathrm{y}$ & $45(41.3)$ & Reference & & & \\
\hline$\geq 65 \mathrm{y}$ & $64(58.7)$ & $2.32(1.30-4.12)$ & .004 & $3.12(1.61-6.04)$ & .001 \\
\hline \multicolumn{6}{|l|}{ Sex } \\
\hline Female & $63(57.8)$ & Reference & & Reference & \\
\hline Male & $46(42.2)$ & $1.45(0.86-2.45)$ & .164 & $1.15(0.67-1.97)$ & .613 \\
\hline \multicolumn{6}{|l|}{ Smoker } \\
\hline Never & $14(12.8)$ & Reference & & Reference & \\
\hline Ever & $95(87.2)$ & $1.53(0.65-3.59)$ & .328 & $1.29(0.52-3.19)$ & .589 \\
\hline \multicolumn{6}{|l|}{ Zubrod } \\
\hline 0 & $61(56.0)$ & Reference & & Reference & \\
\hline 1 & $48(44.0)$ & $0.73(0.43-1.23)$ & .237 & $0.92(0.50-1.70)$ & .798 \\
\hline \multicolumn{6}{|l|}{ FEV1 } \\
\hline$>70 \%$ Predicted & $82(75.2)$ & Reference & & Reference & \\
\hline$\leq 70 \%$ Predicted & $27(24.8)$ & $1.72(0.97-3.04)$ & .065 & $1.09(0.58-2.07)$ & .793 \\
\hline Tumor size $(\mathrm{cm})$ & $\mathrm{n} / \mathrm{a}$ & $1.15(0.94-1.42)$ & .184 & $1.23(0.96-1.59)$ & .105 \\
\hline \multicolumn{6}{|l|}{ Differentiation } \\
\hline Well/moderate & $69(63.3)$ & Reference & & Reference & \\
\hline Poor & $40(36.7)$ & $1.80(1.06-3.06)$ & .029 & $1.46(0.80-2.67)$ & .213 \\
\hline \multicolumn{6}{|l|}{ Histology } \\
\hline $\mathrm{ACA}$ & $73(67.0)$ & Reference & & Reference & \\
\hline SCC & $33(30.3)$ & $2.15(1.26-3.68)$ & .005 & $1.12(0.57-2.22)$ & .741 \\
\hline NSCLC NOS & $3(2.8)$ & $1.60(0.38-6.69)$ & .522 & $1.23(0.26-5.68)$ & .795 \\
\hline \multicolumn{6}{|l|}{ Extent of resection } \\
\hline Lobectomy/bilobectomy & $105(96.3)$ & Reference & & & \\
\hline Sublobar & $4(3.7)$ & $7.58(2.57-22.36)$ & $<.001$ & & \\
\hline \multicolumn{6}{|l|}{ Margin } \\
\hline R0 & $107(98.2)$ & Reference & & & \\
\hline $\mathrm{R} 1$ & $2(1.8)$ & $2.71(0.66-11.18)$ & .169 & & \\
\hline \multicolumn{6}{|l|}{ Ki67 expression* } \\
\hline Low & $12(11.0)$ & Reference & & Reference & \\
\hline Intermediate & $55(50.5)$ & $4.33(1.02-18.41)$ & .047 & $3.91(0.89-17.18)$ & .071 \\
\hline High & $42(38.5)$ & $8.22(1.96-34.52)$ & .004 & $6.12(1.21-30.89)$ & .028 \\
\hline \multicolumn{6}{|l|}{ Adjuvant chemotherapy } \\
\hline None & $91(83.5)$ & Reference & & Reference & \\
\hline Chemotherapy & $18(16.5)$ & $0.39(0.15-0.98)$ & .044 & $0.39(0.15-1.02)$ & .055 \\
\hline
\end{tabular}

$H R$, Hazard ratio; $C I$, confidence interval; $F E V I$, forced expiratory volume in 1 second; $A C A$, adenocarcinoma; $S C C$, squamous cell carcinoma; $N S C L C N O S$, non-small cell lung cancer, not otherwise specified. *Low expression: Ki67 $\leq 7.17 \%$; Intermediate expression: Ki67 7.17\%-25.73\%; High expression: Ki67 >25.73\%. 
TABLE E5. Univariable and multivariable analysis of factors associated with disease-free survival among patients with pathological stage I tumors $(\mathbf{n}=109)$

\begin{tabular}{|c|c|c|c|c|c|}
\hline \multirow[b]{2}{*}{ Variable } & \multirow[b]{2}{*}{$\mathbf{N}(\%)$} & \multicolumn{2}{|c|}{ Univariable } & \multicolumn{2}{|c|}{ Multivariable } \\
\hline & & HR $(95 \%$ CI $)$ & $P$ & HR $(95 \%$ CI $)$ & $P$ \\
\hline \multicolumn{6}{|l|}{ Age } \\
\hline$<65 \mathrm{y}$ & $45(41.3)$ & Reference & & Reference & \\
\hline$\geq 65 \mathrm{y}$ & $64(58.7)$ & $2.06(1.17-3.62)$ & .012 & $2.29(1.27-4.12)$ & .006 \\
\hline \multicolumn{6}{|l|}{ Sex } \\
\hline Female & $63(57.8)$ & Reference & & & \\
\hline Male & $46(42.2)$ & $1.44(0.86-2.43)$ & .167 & & \\
\hline \multicolumn{6}{|l|}{ Smoker } \\
\hline Never & $14(12.8)$ & Reference & & & \\
\hline Ever & $95(87.2)$ & $1.58(0.67-3.70)$ & .294 & & \\
\hline \multicolumn{6}{|l|}{ Zubrod } \\
\hline 0 & $61(56.0)$ & Reference & & & \\
\hline 1 & $48(44.0)$ & $1.32(0.79-2.22)$ & .292 & & \\
\hline \multicolumn{6}{|l|}{ FEV1 } \\
\hline$>70 \%$ Predicted & $82(75.2)$ & Reference & & & \\
\hline$\leq 70 \%$ Predicted & $27(24.8)$ & $1.60(0.91-2.84)$ & .106 & & \\
\hline Tumor size $(\mathrm{cm})$ & $\mathrm{n} / \mathrm{a}$ & $1.14(0.93-1.40)$ & .212 & & \\
\hline \multicolumn{6}{|l|}{ Differentiation } \\
\hline Well/moderate & $69(63.3)$ & Reference & & & \\
\hline Poor & $40(36.7)$ & $1.69(1.00-2.86)$ & .049 & & \\
\hline \multicolumn{6}{|l|}{ Histology } \\
\hline ACA & $73(67.0)$ & Reference & & & \\
\hline SCC & $33(30.3)$ & $1.91(1.12-3.25)$ & .017 & & \\
\hline NSCLC NOS & $3(2.8)$ & $1.41(0.34-5.90)$ & 639 & & \\
\hline \multicolumn{6}{|l|}{ Extent of resection } \\
\hline Lobectomy/bilobectomy & $105(96.3)$ & Reference & & & \\
\hline Sublobar & $4(3.7)$ & $5.62(1.95-16.23)$ & .001 & $3.70(1.27-10.84)$ & .017 \\
\hline \multicolumn{6}{|l|}{ Margin } \\
\hline R0 & $107(98.2)$ & Reference & & & \\
\hline R1 & $2(1.8)$ & $2.62(0.64-10.83)$ & .182 & & \\
\hline \multicolumn{6}{|l|}{ Ki67 expression* } \\
\hline Low & $12(11.0)$ & Reference & & Reference & \\
\hline Intermediate & $55(50.5)$ & $4.29(1.01-18.23)$ & .048 & $4.48(1.04-19.33)$ & .044 \\
\hline High & $42(38.5)$ & $7.56(1.80-31.73)$ & .006 & $8.71(2.04-37.19)$ & .003 \\
\hline \multicolumn{6}{|l|}{ Adjuvant chemotherapy } \\
\hline None & $91(83.5)$ & Reference & & & \\
\hline Chemotherapy & $18(16.5)$ & $0.42(0.17-1.05)$ & .063 & & \\
\hline
\end{tabular}


TABLE E6. Univariable and multivariable analyses of factors associated with disease-free survival among patients with pathological stage I tumors, with inclusion of all clinically relevant variables without elimination $(n=109)$

\begin{tabular}{|c|c|c|c|c|c|}
\hline \multirow[b]{2}{*}{ Variable } & \multirow[b]{2}{*}{$\mathbf{N}(\%)$} & \multicolumn{2}{|c|}{ Univariable } & \multicolumn{2}{|c|}{ Multivariable } \\
\hline & & HR $(95 \%$ CI $)$ & $P$ & HR $(95 \%$ CI $)$ & $P$ \\
\hline \multicolumn{6}{|l|}{ Age } \\
\hline$<65 \mathrm{y}$ & $45(41.3)$ & Reference & & Reference & \\
\hline$\geq 65 \mathrm{y}$ & $64(58.7)$ & $2.06(1.17-3.62)$ & .012 & $2.64(1.40-5.00)$ & .003 \\
\hline \multicolumn{6}{|l|}{ Sex } \\
\hline Female & $63(57.8)$ & Reference & & Reference & \\
\hline Male & $46(42.2)$ & $1.44(0.86-2.43)$ & .167 & $1.20(0.71-2.05)$ & .494 \\
\hline \multicolumn{6}{|l|}{ Smoker } \\
\hline Never & $14(12.8)$ & Reference & & Reference & \\
\hline Ever & $95(87.2)$ & $1.58(0.67-3.70)$ & .294 & $1.34(0.54-3.31)$ & .528 \\
\hline \multicolumn{6}{|l|}{ Zubrod } \\
\hline 0 & $61(56.0)$ & Reference & & Reference & \\
\hline 1 & $48(44.0)$ & $1.32(0.79-2.22)$ & .292 & $0.94(0.52-1.70)$ & .826 \\
\hline \multicolumn{6}{|l|}{ FEV1 } \\
\hline$>70 \%$ Predicted & $82(75.2)$ & Reference & & Reference & \\
\hline$\leq 70 \%$ Predicted & $27(24.8)$ & $1.60(0.91-2.84)$ & .106 & $1.15(0.62-2.12)$ & .667 \\
\hline Tumor size $(\mathrm{cm})$ & $\mathrm{n} / \mathrm{a}$ & $1.14(0.93-1.40)$ & .212 & $1.19(0.93-1.53)$ & .162 \\
\hline \multicolumn{6}{|l|}{ Differentiation } \\
\hline Well/moderate & $69(63.3)$ & Reference & & Reference & \\
\hline Poor & $40(36.7)$ & $1.69(1.00-2.86)$ & .049 & $1.35(0.75-2.44)$ & .321 \\
\hline \multicolumn{6}{|l|}{ Histology } \\
\hline $\mathrm{ACA}$ & $73(67.0)$ & Reference & & Reference & \\
\hline $\mathrm{SCC}$ & $33(30.3)$ & $1.91(1.12-3.25)$ & .017 & $1.05(0.54-2.04)$ & .892 \\
\hline NSCLC NOS & $3(2.8)$ & $1.41(0.34-5.90)$ & .639 & $1.09(0.24-5.01)$ & .911 \\
\hline \multicolumn{6}{|l|}{ Extent of resection } \\
\hline Lobectomy/bilobectomy & $105(96.3)$ & Reference & & & \\
\hline Sublobar & $4(3.7)$ & $5.62(1.95-16.23)$ & .001 & & \\
\hline \multicolumn{6}{|l|}{ Margin } \\
\hline R0 & $107(98.2)$ & Reference & & & \\
\hline $\mathrm{R} 1$ & $2(1.8)$ & $2.62(0.64-10.83)$ & .182 & & \\
\hline \multicolumn{6}{|l|}{ Ki67 expression* } \\
\hline Low & $12(11.0)$ & Reference & & Reference & \\
\hline Intermediate & $55(50.5)$ & $4.29(1.01-18.23)$ & .048 & $3.96(0.91-17.28)$ & .068 \\
\hline High & $42(38.5)$ & $7.56(1.80-31.73)$ & .006 & $6.00(1.21-29.81)$ & .028 \\
\hline \multicolumn{6}{|l|}{ Adjuvant chemotherapy } \\
\hline None & $91(83.5)$ & Reference & & Reference & \\
\hline Chemotherapy & $18(16.5)$ & $0.42(0.17-1.05)$ & .063 & $0.43(0.17-1.12)$ & .084 \\
\hline
\end{tabular}

